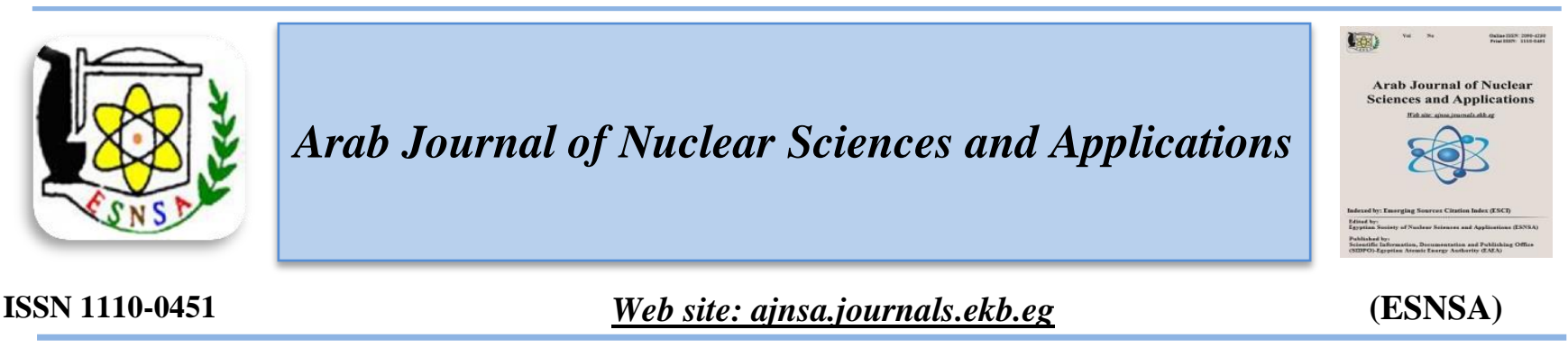

\title{
Ultrastructure Deformation of Flight Muscles and Bioenergetics Changes in Honey Bee Workers Treated with Pesticides
}

\author{
Eman A. Mahmoud ${ }^{(1)^{*}}$, Mona F. Abd El-Aziz ${ }^{(2)}$ and Thanaa M. Sileem ${ }^{(1)}$ \\ ${ }^{(1)}$ Biological Applications Department, Nuclear Research Center, Atomic Energy Authority Egypt \\ ${ }^{(2)}$ Entomology Department, Faculty of Science, Benha University, Egypt
}

Received $23^{\text {rd }}$ Dec. 2019 Beehives are exposed to the risk of pesticide contamination by honey bee workers who transport polluted Accepted $11^{\text {th }}$ June pollens and nectar to the hive. This work illustrated the hazardous effects of two pesticides namely, 2020 avermectin (broklen pure) and chlorpyrifos (ictafos) on flight muscles of bee workers, Apis mellifera. The normal microfibrillar muscles are made up of bundles fiber. Each fiber consists of many sarcostyles covered with a layer of sarcolemma. There are few amounts of sarcoplasmic reticulum, autophagic vacuoles and tracheoles between sarcostyles. Sarcosomes are scattered among sarcostyles in double rows with obvious cristae as slab-like structures or huge, ranging from 0.6 to $1.7 \mu$ in diameter and from 1.3 to $3.3 \mu$ in length. Nuclei are deposited between the sarcostyles with rounded nucleolus. After being treated with broklen pure, the sarcostyles appeared with damaged nuclear envelop and breakdown of chromatin. Some fragmentation of nucleus, cellular membranes, sarcosomes and sarcoplasmic reticulum are shown. Besides, the escape of sarcosomes contents onto the surface of the surroundings. While, those treated with ictafos illustrated irreversible damaged degeneration and necrosis of the sarcostyles, sarcosomes and nuclei. Organelles were decomposed until they appear as intracellular fluid. Additionally, ictafos induced more significant effects on bee workers bioenergetics than broklen pure. It induced not only a significant reduction in gross energy, crude fiber, but also a highly significant reduction in crude protein. However, it induced a highly significant increase in nitrogen free extracts compared with the control. Therefore, muscle fibers of insects treated with ictafos appeared more susceptible than those treated with broklen pure.

Keywords: Apis mellifera / Flight muscles / Fine structure / Pesticides /Bioenergetics

\section{Introduction}

Honey bees are very important to the survival of humanity and most important pollinators worldwide. Only about $15 \%$ of the world's crops are pollinated by a few managed bee species, e.g. A.mellifera, while the rest are pollinated by unmanaged solitary bees and other wildlife [1]. Additionally, a honey bee produces valuable products such as honey, royal jelly, and bee pollen[2]. In agricultural systems, bees are exposed to many pesticides when they collect nectar and pollen. Most pesticides are highly toxic to bees and other pollinators [3]. The first international forum for the Egyptian beekeepers (2009) stated that Egypt has 1.3 million hives (7700 are mud hives, and approximately 270,000 beekeepers). It is estimated to be one of the most influential in the Middle East and Africa. Egyptian beekeepers based along the Nile River have increased colony losses over winter seasons with no clear cause for

Corresponding author: e.mahmoud11@yahoo.com

DOI: 10.21608 /ajnsa.2020.21369.1315

CScientific Information, Documentation and Publishing Office (SIDPO)-EAEA 
this phenomenon [4]. During the1990s, 15-20\% of hives destroyed. Losses were attributed to a range of factors such as diseases, pathogens and pesticides, in the mid-2000s, losses have risen to $43 \%$ in some locations [5]. Among the pesticides that are frequently used in Egypt for pest control are chlorpyrifos and avermectins with commercial names ictafos and broklen pure, respectively. Ictafos is one of the most widely applied organic phosphorous pesticides in Egypt with a general use. It is registered for agricultural uses with 64 crops in Egypt [6]. Chlorpyrifos methyl is registered in Egypt under other trade names including, Ictan 50\% EC, Pyrodan 50\% EC, Reldan 50\% EC, and Relozed 50\% EC to control the Egyptian cotton leaf worm and aphids[7]. Avermectins are a family of macrocyclic lactone homologues of those produced by the soil microorganisms, Streptomyces avermitilis[8]. Biochemical assays that have been employed for environmental biomonitoring represent a valuable tool to investigate pesticide exposure and effects. As bioindicator organisms are sensitive to pollutants, analysis of different ecotoxicological biomarkers in these species gives important information about the contamination of the environment. Biomarkers are thus defined as measurable modifications in bioindicator organisms that can be related to exposure to contaminants [9]. The potential effect of pesticides on bee colonies was estimated in five agricultural Egyptian governorates. The influence of 14 organic phosphorous insecticides (OPs) on $A$. mellifera, and hive matrices (honey and pollen) as well as the potential for lethality from direct and dietary exposure were studied [5]. This study indicated that chlorpyrifos represents the third most detected OP in 14\% of the total samples. The bioenergetic condition of an insect is dynamic and influenced by a variety of factors. It effects on large spectrum of topics ranging from cell biology, metabolism, and physiology, to the interaction of the host with its microbiome, to behavior and ecology. The present investigation aimed to compare the effects of two pesticides namely, ictafos and broklen pure on the flight muscles and bioenergetics of A. mellifera.

\section{MATERIALS AND METHODS}

Bee Colony

Honey bee workers were obtained from colonies reared in Central Laboratories-Isotope Applications Division, Nuclear Research Center, Atomic Energy Authority, Inshas, Egypt.

\section{Pesticides}

Ictafos $50 \%$ EC- chlorpyrifos-methyl $\left(\mathrm{C}_{7} \mathrm{H}_{7} \mathrm{Cl}_{3} \mathrm{NO}_{3} \mathrm{PS}\right)$ - and broklen pure 5\%WPavermactin benzoate-were purchased from the International Company for Chemicals \& Commercial Agencies (ACTA) Giza, Egypt.

\section{Bioassay}

To determine the oral toxicity of the two pesticides, bee workers were captured while returning from the field to the hive. Three replicates were used for each treatment and control groups (30 insects/ treatment, ten insects /replicate) were preserved in clean cages containing food (a piece of cotton saturated with heavy sucrose syrup) in small Petri dish. Stock solutions of ictafos and broklen pure were prepared and diluted in distilled water. The final concentrations for each treatment dose were obtained by adding an appropriate concentrated solution of pesticides to heavy sucrose syrup of bees. For each pesticide, five concentrations were performed on the tested bee workers to detect sublethal concentration that kills half of the population values $\left(\mathrm{LC}_{50}\right)$ after $24-48 \mathrm{hrs}$ of treatment.

Preparation of flight muscles for transmission electron microscopy

Ictafos and broklen pure $\mathrm{LC}_{50}$ treated and untreated bee workers were dissected in a saline solution. The flight muscles were removed and fixed in $3 \%$ phosphate buffered gluteraldehyde pH7.4 at $4{ }^{\circ} \mathrm{C}$ for two hours, washed by phosphate buffer $\mathrm{pH} 7.4$ and the specimens were post fixed in freshly prepared $1 \%$ osmium tetroxide in phosphate buffer for1-2 hrs. Specimens were 
dehydrated in ascending grades of ethanol concentration (10 minutes in each concentration) and completed by propylene. Specimens were then embedded in plastic capsules. Embedding mixture formed of $10 \mathrm{ml}$ of araldite (the embedding material), $8 \mathrm{ml}$ of the hardener dodenyl succinic anhydride (DDSA) were both mixed properly and kept in a $60{ }^{\circ} \mathrm{C}$ oven for 10 minutes to eliminate air bubbles. $0.4 \mathrm{ml}$ - about 18 drops of accelerator tridimethylaminomethylphenol (DMP) were then added and mixed. Ultrathin sections (50 nm thick) were obtained from selected blocks and mounted on copper grids, which were kept in Petri- dishes and stained with uranyl acetate for 20 minutes followed by lead citrate for 10 minutes. Examination was conducted by Philips 201transmission electron microscope at $60-80 \mathrm{Kv}$ in transmission Electron Microscope Unit at Medical Military Academy. Finally, electron micrographs were taken at various magnifications [10].

\section{Assessment of bioenergetics}

Ictafos and broklen pure $\mathrm{LC}_{50}$ of the treated and untreated bee workers were prepared to calculate the gross energy. All samples were dried in oven at temperature $37{ }^{\circ} \mathrm{C}$ for 2-4 days. Then, samples were weighed and caloric equivalent was determined using pellets pressed from powdered materials (Wiley Intermediate Mill, $20 \mathrm{mish}$ ) in programmable isothermal jacket bomb calorimeter (Julious Peter Berlin, Germany) following the standard methods of gross caloric values of solid fuel [11]. The gross energy (GE) was calculated by the equation [12]:

$\mathrm{GE}=0.0226 \mathrm{CP}+0.04070 \mathrm{EE}+0.0192 \mathrm{CF}+0.0177 \mathrm{NE}$

F. As $\mathrm{gm} / \mathrm{Kj}$.

$\mathrm{CP}=$ crude protein, $\mathrm{EE}=$ ether extract, $\mathrm{CF}=$ crude fiber, $\mathrm{NFE}=$ nitrogen free extracts

$\mathrm{NFE}=\mathrm{OM}-(\mathrm{CF}+\mathrm{CP}=\mathrm{EE}) \quad \mathrm{OM}=$ organic matter

\section{Statistical Analysis}

Mortality data after 24-48 hrs of treatment was corrected by Abbott's formula and analyzed by Probit analysis [13] to obtain $\mathrm{LC}_{50}$. By using (Origen lab program version 7.5), data were expressed as means \pm standard errors. Statistical significance of differences between individuals, means was determined using one way ANOVA test. Levels of significance of each experiment were stated to be significant at $(\mathrm{P} \leq 0.05)$, highly significant $(\mathrm{P} \leq 0.01)$ and very highly significant $(\mathrm{P} \leq 0.001)$.

\section{RESULTS}

Sublethal concentrations of the tested pesticides against honey bee workers showed that ictafos was more toxic to bee workers at $\mathrm{LC}_{50}(0.003 \mu / \mathrm{L})$ than broklen pure at $2 \mathrm{ppm}$ which induced $50 \%$ mortality.

\section{Fine Structure of Normal Flight Muscles}

Semithin section of normal thoracic muscles illustrated that microfibrillar muscles are made up of very large striated fiber bundles, which correspond by the parallel fibrillae of the other organelles (Fig.1A). Each fiber consists of a number of sarcostyles about 3 microns in diameter with a thick layer of sarcoplasmic membrane or sarcolemma, but glycogen particles could not be detected (Fig.2B). Each sarcostyle consists of alternating isotropic and anisotropic segments (light and dark-staining discs). Light disc about 0.88 microns in diameter and is traversed by a $\mathrm{Z}$ line membrane (telophragma) attached all-round the fiber (Fig.2A). Dark disc is thin with an average diameter of 0.38 microns. There are few amounts of sarcoplasmic reticulum, autophagic vacuoles and tracheoles between sarcostyles (Fig.2B, E). Also, sarcosomes (mitochondria) are scattered among sarcostyles in double rows with obvious cristae. Sarcosomes are very large in size, conspicuous as slab-like structures, huge, ranging from about 0.6 to1.7 microns in diameter and from 1.3 to 3.3 microns in length (Fig.2B). In some parts, the sarcosomes arranged like plexus between the sarcostyles (Fig.2C). The sheath of plasma membrane or sarcolemma covered the surface of each individual fiber (Fig.2B). Nuclei are deposited and scattered throughout sarcoplasm between the fibers (Fig.2E). Nucleoplasm has an obvious rounded nucleolus with patches of chromatin arranged either around the nuclear 
membrane in a large amount or scattered inside the nucleoplasm. A number of ribosomes and sarcoplasmic reticulum were scattered in the Fine structure of the treated flight muscles with pesticides

Semithin section of bee workers treated with broklen pure showed degenerative and vacuolation of muscle bundles (Fig.1B). Fine structure showed the disruption of sarcostyle with loss of its striation (Fig.3A, D). Damage of nuclear envelop with breakdown of chromatin with pyknosis (chromatin condenses into solid mass) was observed (Fig.3A, C). Some fragmentation of nucleus, damaged cellular membranes, sarcosomes and sarcoplasmic reticulum were showed. Also, scape of sarcosomes contents onto surface of surroundings (Fig.3E, F). Semithin section of flight muscles treated with ictafos showed loss of striation in the outer border but the inner border became highly irregular with projection denoting disruption and degenerative changes (Fig.1C). Fine structure illustrated nucleus which was encircled by bilayers of nuclear membrane (Fig.2D, E).

irreversible damaged degeneration and necrosis of the sarcostyles, sarcosomes and nuclei (Fig.4A-C). Organelles were decomposed until they appear as intracellular fluid and disruption of sarcolemma (Fig.4D, E).

\section{Bioenergetics of bee workers}

Table (1) shows that ictafos has a stronger effect on bioenergetics of bee workers than that of broklen pure. Ictafos induced a significant reduction $(\mathrm{P} \leq 0.05)$ in $\mathrm{GE}, \mathrm{CF}$ also a highly significant reduction $(\mathrm{P} \leq 0.01)$ in $\mathrm{CP}$ compared with the control insects. However, it induced very highly significant increase $(\mathrm{P} \leq 0.001)$ in NFE than the control. At the same time non-significant changes were observed in insects treated with broklen pure except for NFE which showed a more significant reduction at $\mathrm{P} \leq 0.001$ than that of the untreated insects. 

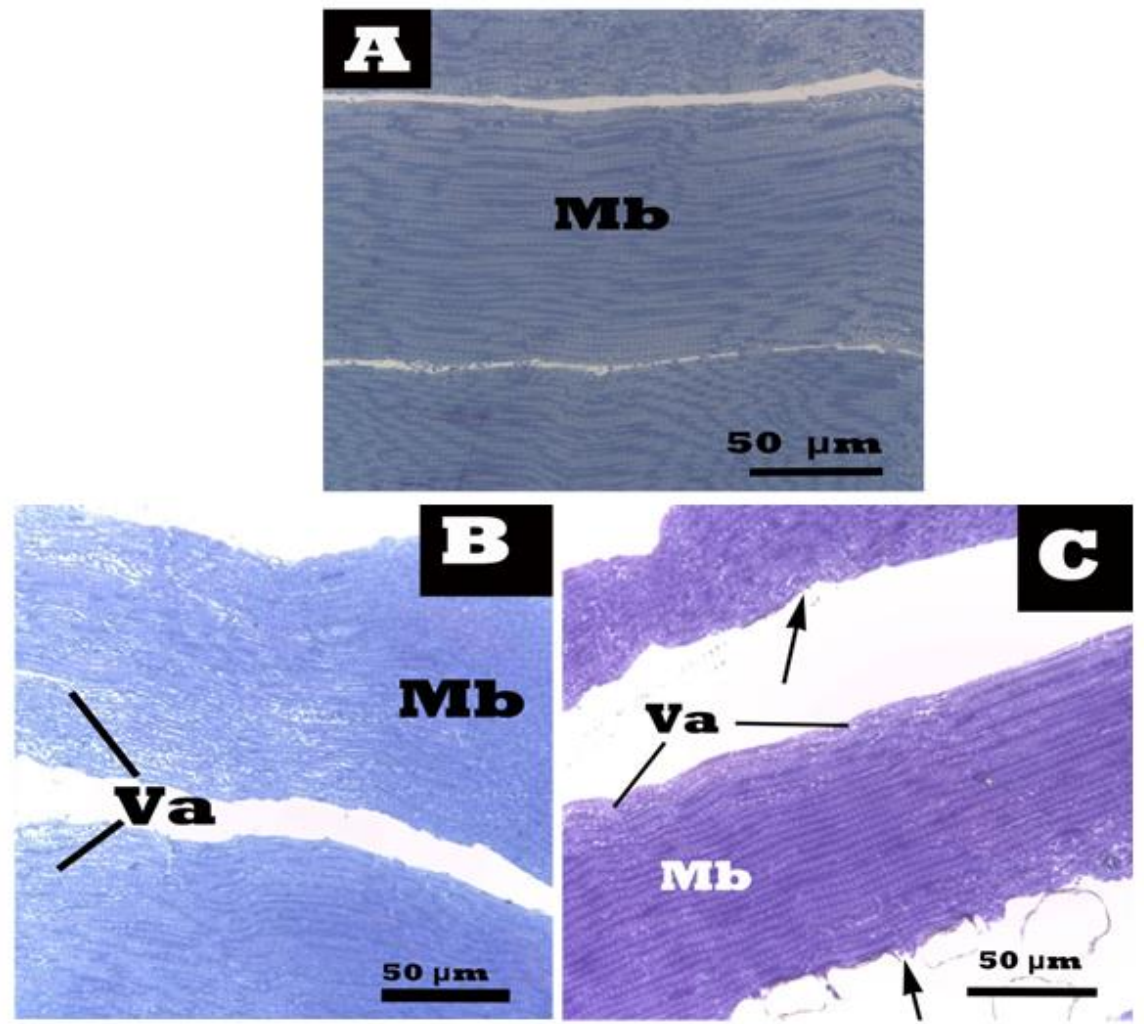

Figure (1): S emithin sections in flight muscle of bee workers. (A)Normal striated muscle bundles (Mb); (B) Effect of broklen pure appeared vacuoles ( $\mathrm{Va}$ ) in the muscle bundles with loss of striation; (C) Effect of ictafos showed vacuoles in thin muscle bundles and the inner border is highly irregular with projection denoting disruption (single arrows). 


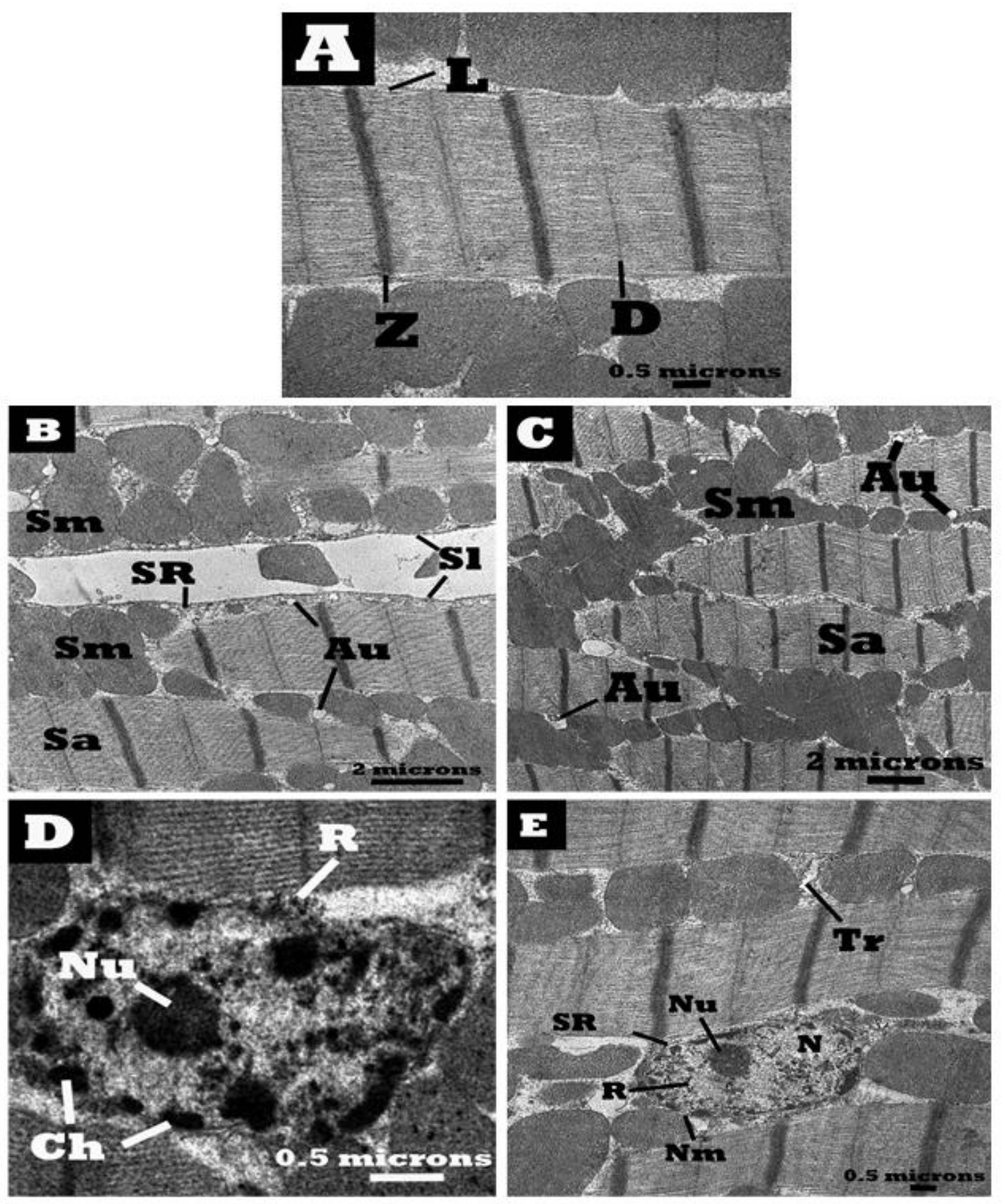

Figure (2): Ultrastructural aspects on muscle Fiber of normal bee workers. (A) Showing the structure of sacrostyle (Sa), dark disc (D), light disc (L)and $\mathrm{Z}$ line membrane $(\mathrm{Z})$; $(\mathrm{B}, \mathrm{C})$ The sarcosomes $(\mathrm{Sm})$ arranged between the sarcostyles like two layers or plexus and the presence of autophagic vacuoles (Au), sarcoplasmic reticulum (SR) and sarcolemma (S1); (D,E) showed the nuclei $(N)$ with different shapes of chromatin patches $(\mathrm{Ch})$, ribosomes $(R)$, round nucleolus $(\mathrm{Nu})$, and tracheole $(\mathrm{Tr})$ be tween the sarcosomes. 

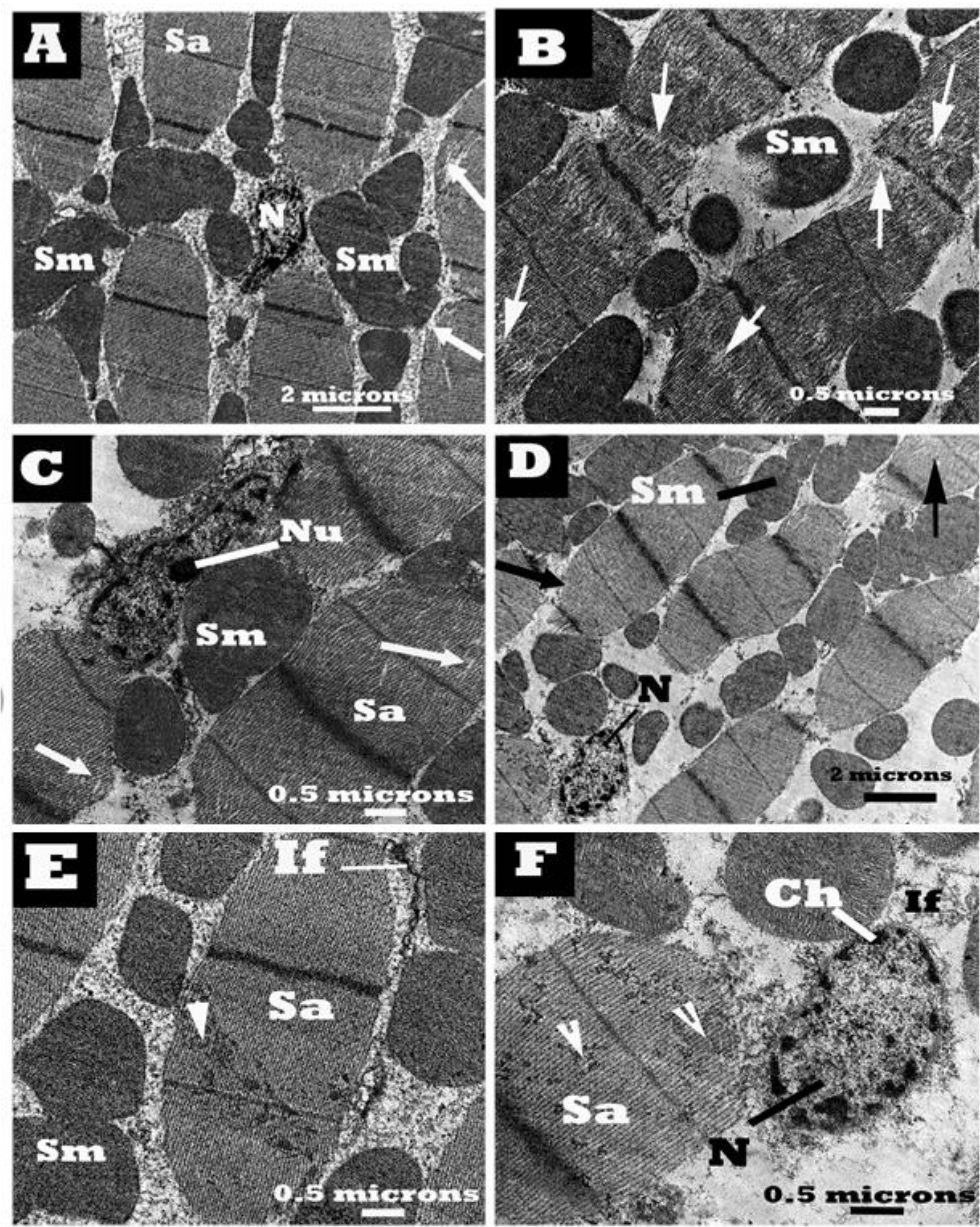

Figure (3): Ultrastructural aspects on muscle fiber of bee workers treated with broklen pure. (A-D) disuption of sarcostyles (Sa) (single arrows), sarcosomes ( $\mathrm{Sm}$ ) and damage of nuclei (N); (E,F)Damage of cellular content with scape the interstitial fluid (If) onto surface of surroundings (arrows heads), damaged nucleus $(\mathrm{N})$ and chromatin (Ch). 

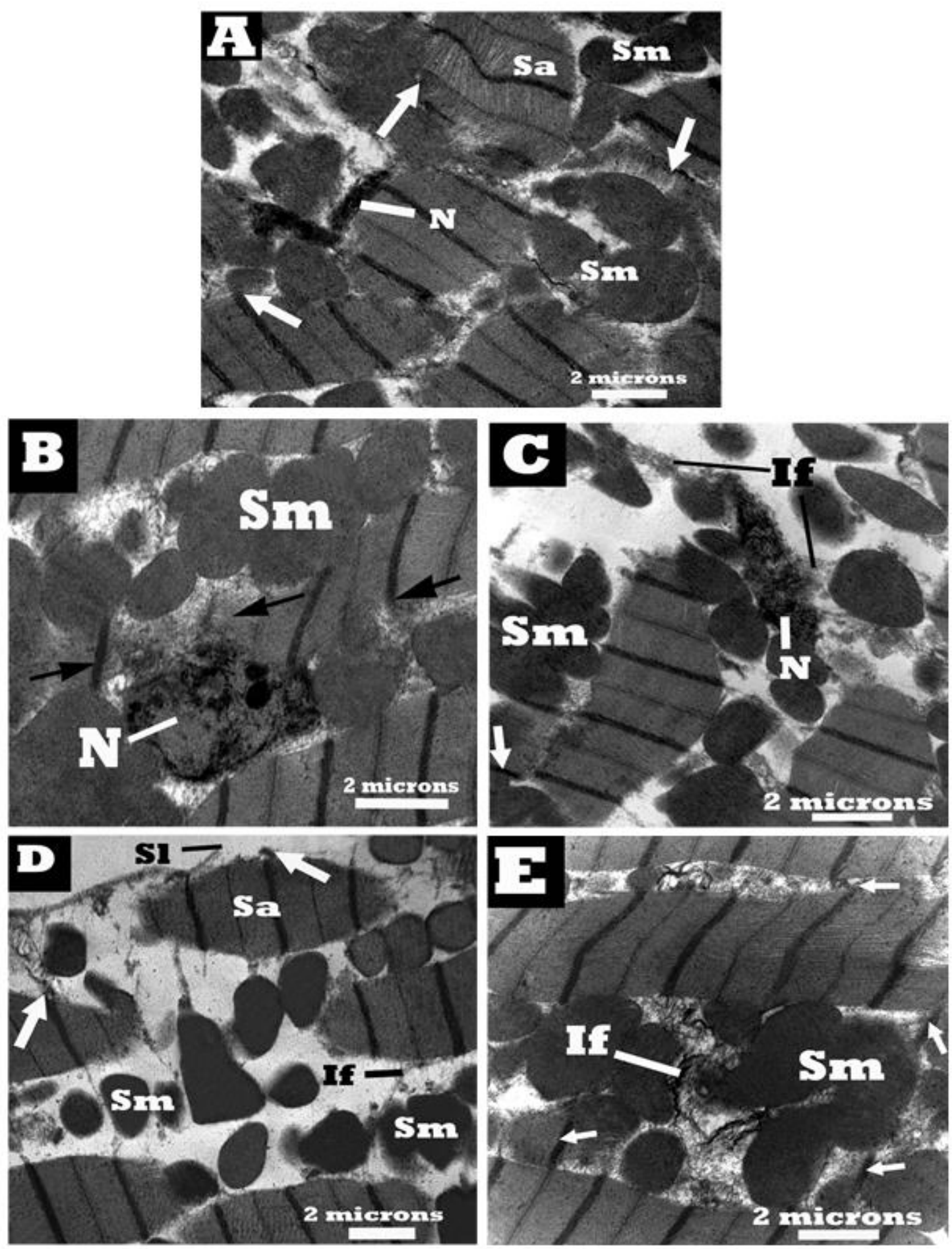

Figure (4): Ultrastructural aspects on muscle fiber of bee workers treated with ictafos. (A-E) Appeared irreversible damage degeneration and necrosis of sarcosomes $(\mathrm{Sm})$, nuclei $(\mathrm{N})$, sarcostyles (Sa)(single arrows) and the presence of large amount of interstitial fluid (If) and disuption of sarcolemma (S1). 
Table (1): Evaluation of bioenergy and the chemical composition of bee workers treated with $\mathrm{LC}_{50}$ of the pesticide under laboratory conditions of temperature $30 \pm 2{ }^{\circ} \mathrm{C}$

\begin{tabular}{llll}
\hline & Control & Broklen pure $(\mathbf{2} \mathbf{~ p p m})$ & Ictafos $(\mathbf{0 . 0 0 3} \boldsymbol{\mu} / \mathbf{L})$ \\
\hline Live wt• & $95.9 \pm .0 .9$ & $85.3 \pm 1.4^{*}$ & $71.7 \pm 1.2 * *$ \\
Dry wt• & $19.3 \pm 0.98$ & $18.5 \pm 1.1$ & $16.2 \pm 0.52^{*}$ \\
Ash & $0.99 \pm 0.17$ & $0.94 \pm 0.56$ & $0.543 \pm 0.18^{*}$ \\
OM & $18.30 \pm 1.08$ & $17.56 \pm 0.96$ & $16.66 \pm 0.57$ \\
CP & $12.94 \pm 0.85$ & $10.219 \pm 0.57$ & $6.38 \pm 0.055^{* *}$ \\
CF & $3.52 \pm 0.9$ & $2.29 \pm 0.4$ & $1.69 \pm 0.4^{*}$ \\
EE & $1.67 \pm 0.7$ & $1.506 \pm 0.7$ & $1.18 \pm 0.2$ \\
NFE & $0.164 \pm 0.09$ & $3.53 \pm 0.67 * * *$ & $7.399 \pm 1.1 * * *$ \\
GE/insect & $431.16 \pm 2.3$ & $399.05 \pm 3.1$ & $355.7 \pm 2.5$ \\
\hline
\end{tabular}

*Significant $(\mathrm{P} \leq 0.05), * *$ High significant $(\mathrm{P} \leq 0.01), * * *$ Very high significant $(\mathrm{P} \leq 0.001)$.

-wt mg/insect, Crude protein (CP), Ether extract (EE), Crude fiber (CF), Nitrogen free extracts (NFE), Gross energy $(\mathrm{GE})$ and Organic matter $(\mathrm{OM}) . \mathrm{NFE}=\mathrm{OM}-[\mathrm{CF}+\mathrm{CP}+\mathrm{EE}]$

\section{Discussion}

The extent of honey bee loss and the negative impacts of pesticides on A. mellifera have been studied by several authors who indicated that pesticides were one of the main causes of pollinators decline $[14,15,16]$. Forage bees can be exposed directly through contact with pesticides or indirectly by consuming pesticide residue in nectar and pollen from flowers [17]. An entire colony may be exposed to pesticides by collecting and transporting pollen polluted by forage bees to the hive [18]. In the current bioassay, oral toxicity assay, clearly indicated that ictafos was more toxic to the bee workers than broklen pure. Consequently, muscles of bee workers treated with $\mathrm{LC}_{50}$ of ictafos appeared more degenerated, disrupted and highly irregular than those treated with broklen pure. Comparative toxicity of several chemical pesticides; spinosad, chlorpyrifos, emamectin benzoate, cypermethrin, quinalphos, endosulfan and Lambda cyhalothrin against pests and some natural enemies on eggplant was studied[19]. This study found that spinosad was safe for natural enemies, while other pesticides proved to be toxic to all of them. While, emamectin benzoate was the most effective against many agriculture pests compared to the other tested compounds. Johnson et al.[20] proved that chlorpyrifos was highly toxic to honey bees which caused $100 \%$ mortality after $6 \mathrm{hrs}$ at high concentrations. Also, another comparative toxicity test was performed on three species of honey bees, Apis florea, Apis dorsata, and A. mellifera to verify long-term survival of honey bees when exposed to different pesticides. The results showed that chlorpyrifos and imidacloprid were the most toxic at their high dose for A. florea, whereas chlorpyrifos was the most toxic at high a dose for A.dorsata [21]. Emamectin benzoate is a stomach poison in addition to its contact mode of action [22].

Maximization of energetic efficiency may be an adaptation to a limited flight-cost budget [23]. The current results showed that the gross energy stored in the body of bee workers significantly affected in the case of workers treated with ictafos than broklen pure. Proteins are important organic substances required by organisms in tissue building and play an important role in energy metabolism [24]. Flight muscles of bees are skeletal striated muscles very similar in organization to the vertebrate skeletal muscles [25]. Honey bee workers become ready to fly out of the nest 3-5 days after have emerged [26, 27]. Although in colonies, they become foragers only when they are about 20-25 days old. Ability to fly soon after emergence might explain the more developed mitochondria at the emergence time in this species. Workers need a physiological maturation before the onset of flight. This maturation is morphologically expressed mainly by a thickening of the muscle fiber due to 
myofibril enlargement and increase in mitochondrial size and cristae [28]. Where, energy for flight is produced non-aerobically in the muscle sarcosomes. The speed of ictafos action may well rule out any concept of lysosomal stimulation, indicating that the pesticides may act directly on the membrane, causing disintegration by disruption of $\mathrm{Ca}^{2+}$ ATP ase transporting sites.

\section{Conclusion}

According to these results, it was found that ictafos has more degenerative effects on the flight muscle bundles than broklen pure that affect bee vitality and the insect's capability to fly. Also, ictafos treatment led to decrease of crude protein, crude fiber and nitrogen free extracts. This might affect on all biosynthesis, enzyme production, and immunity to disease. It is clear that this pesticide has a negative impact on beneficial insects, which directly or indirectly affect human health and the country's economic resources. Finally, restricting the use of these pesticides, especially ictafos, for agricultural pest control is recommended.

\section{Acknowledgement}

The authors greatly appreciate Dr. Mohamed Mostafa in the Biological Applications Department, Nuclear Research Center, Atomic Energy Authority, Cairo - Egypt, for helping to analyze and calculate bioenergetics and his great efforts.

\section{References}

1. Almanza,M.T.F. (2007) Management of Bombusatratus bumble bees to pollinate Lulo (Solanumquitoense L.), a native fruit from the Andes of Colombia, Dissertation, University of Bonn.

2. Klein, A.M., Vaissière, B.E. , Cane,J.H. , Steffan Dewenter, I., Cunningham,S. A., Kremen, C. and Tscharntke,T.(2007) Importance of pollinators in changing landscapes for world crops.Proceedings of the Royal Society B: Biological Sciences, 274(1608),303-313.
3. Blacquière, T., Smagghe, G., Van- Gestel, C.A.M. and Mommaerts, V. (2012) Neonicotinoids in bees: A review on concentrations, side-effects and risk assessment, Ecotoxicology , 21, 973-992.

4. Hassan, A. R. (2009) Proceedings of the $4^{\text {th }}$ Coloss Conference, Global bee colony disorder and threats insect pollinators.

5. Al- Naggar, Y., Garry, C., Vogt, A., Naiem, E., Mohamed, M., Seif, A. and Giesy, J.P. (2015) Organophosphorus insecticides in honey, pollen and bees (Apis melliferaL.) and their potential hazard to bee colonies in Egypt, Ecotoxicology and Environmental Safety, $114,1-8$.

6. El-Marsafy, A. M.(2004) Risk assessment of dietary exposure to chlorpyrifos residues onsomefruits, vegetables and herbs in Egypt during 2002. Journal of Advanced Agriculture Research, 775-787.

7. Malr, (2010) Catalog of recommended pesticides to control pathogenic-pests, Ministry of Agriculture and Land Reclamation, Cairo, Egypt.

8. Jansson,R.K., Brown, R., Cartwright, B., Cox, D., Dunbar, D.M., Dybas, R.A., Eckel, C., Lasota, J.A., Mookerjee, P.K., Norton, J.A., Peterson, R.F., Starner, V.R. and White, S. (1997) Emamectin benzoate: a novel avermectin derivative for control of lepidopterous pests in A Sivapragasam [ed.], Proceedings of the 3rd International Workshop on Management of Diamondback Moth and Other Crucifer Pests. Mardi, Kuala Lumpur, Malaysia,171-177.

9. Lagadic,L.,Caquet,T.and Ramade,F.(1994) The role of biomarkers in environmental assessment.Invertebrate populations and communities, Ecotoxicology, 3,193-208.

10. Hafez, S.E. (1991) Histological, cytological and histochemical studies on the effect of some insecticides on the desert locust, Schistocerca gregaria, Ph.D. Thesis, Entomology Department, Faculty of Science, Ain Shams University. 
11. Astm, (1973) Sanders methods of test for gross caloric values of solid fuel by the isothermaljacket bomb calorimetric' D 3286.

12. Maff, (1975) Technology Bulletin.33.Her Majesty's Stationery Office, London.

13. Finney, D.J. (1971) Probit Analysis. 3rd Edition, Cambridge University Press, Cambridge.

14. Abramson, C., Aquino, I., Ramalho, F. and Price, J.(1999) The effect of insecticides on learning in the Africanized honey bee (Apis mellifera L.), Archives of Environmental Contamination and Toxicology, 37, 529-535.

15. Chauzat, M. P., Faucon, J.P., Martel, A. C., Lachaize , J., Cougoule, N. and Aubert, M. (2006) A survey of pesticide residues in pollen loads collected by honey bees in France, Journal of Economic Entomology, 99, 253262.

16. Da-Silva, I.P, Oliveira, F.A. S., Pedroza, H. P., Gadelha, I.C.N. and Melo, M. M. (2015) Pesticide exposure of honeybees (Apis mellifera) pollinating melon crops, Apidologie, 46 (6), 703-715.

17. Rortais, A., Arnold, G., Halm, M. P. and Touffet- Briens, F. (2005) Modes of honeybees exposure to systemic insecticides: estimated amounts of contaminated pollen and nectar consumed by different categories of bees, Apidologie, 36, 71-83.

18. Villa, S., Vighi, M. , Finizio, A. and Bolchi Serini, G. (2000) Risk assessment for honey bees from pesticide-exposed pollen, Ecotoxicology, 9, 287-297.

19. Kaul, V., Shankar, U. and Khushu , M.K. (2009) Bio-Intensive Integrated Pest Management in Fruit Crop Ecosystem. In: Integrated Pest Management: Innovation-
Development Process. Springer Netherlands, 631-666.

20. Johnson, R. M., Ellis, M. D., Mullin, C.A. and Frazier, M. (2010) Pesticides and honey bee toxicity-USA, Apidologie , 41,312-331.

21. Husain, D., Qasim, M., Saleem, M., Akhter, M. and Khan, K. A. (2014) Bioassay of insecticides against three honey bee species in laboratory conditions, Cercetări Agronomice in Moldova, 158,69-79.

22. Birah, A., Srivastava, R. C., Subhash, C.S. K. and Ahmed, Z. (2008) Toxicity evaluation of emamectin benzoate against tobacco caterpillar (Spodopterautura) by three different assay.Techniques, Indian Journal of Entomology, 70,200-205.

23. Schmid-Hempel, P., Kacelnik, A.,Houston.A.I. (1985) Honeybees maximize efficiency by not filling their crop, Behavioral Ecology and Sociobiology, 17, 61-66.

24. Pang- Hang, Y., Jian, S. , Amartalingam, R. and Choon- Fah, J. B. (2008) Boric acid levels in fresh noodles and fish ball. American journal of Agricultural and Biological Sciences , 3, 476-481.

25. Smyth,T.R. (1985) Muscle system. In: Blum, M.S. (Ed.), Fundamental of insect physiology. 227-252.

26. Free, J.B. (1980) Organizac, Social de Apis mellifera. Ed. Universidade de Sano Paulo, Sano Paulo,79.

27. Winston, M.L.(1987) The Biology of Honey Bee. Harvard University Press, Cambridge, Massachusetts, 89 .

28. Mortiz, R.F. (1988) Biochemical changes during honeybee flight muscle development. In: Nachtigall, W. (Ed.), The Flying Honeybee; Aspects of Energetics, Stuttgart, 51-65 